\title{
ROLE OF ANIMAL MODELS IN PERIODONTAL RESEARCH - A REVIEW
}

\author{
SARAH BANU ${ }^{1}$, JAIGANESH RAMAMURTHY²
}

${ }^{1}$ Department of Periodontics, Saveetha Dental College and Hospitals, Saveetha Institute of Medical and Technical Sciences, Saveetha University, Chennai - 600 077, Tamil Nadu, India. ${ }^{2}$ Department of Periodontics, Saveetha Dental College and Hospitals, Saveetha Institute of Medical and Technical Sciences, Saveetha University, Chennai - 600 077, Tamil Nadu, India. Email: dr.r.jaiganesh@gmail.com

Received: 09 March 2018, Revised and Accepted: 17 April 2018

ABSTRACT

Periodontal diseases require treatment at an early stage to prevent further damage and aggravation of the disease. The most commonly seen periodontal diseases are gingivitis and periodontitis. Animals have contributed a major role in studying the different periodontal diseases and providing a proper treatment. Periodontal diseases are either induced in these experimental animal models or can be seen naturally. Different drugs are tested on the animals induced by the disease to find the most effective treatment for that particular disease. Different animals such as mice, rats, pigs, rabbits, hamsters, and rodents are used for the periodontal research. Different animals show a different reaction while some animals show no reaction. Each animal has its own advantages and disadvantages. The use of large animals brings a limitation in the due to its housing difficulties. Animals for periodontal research are chosen depending on their similarity with that of human anatomy and physiology. The use of these animals will help to replicate the disease seen in humans in a better and more accurate way. This will improve the treatment outcome and the prognosis of the disease. The drugs used can, hence, give a better idea about the effect it would have on the human body depending on the effects it shows on the animal models. Hence, the use of appropriate animals for the periodontal research is important to design a better treatment for these diseases. Hence, animal models play an important role in the periodontal research.

Keywords: Animal models, Periodontal disease, Periodontal research, Gingivitis, periodontitis.

(C) 2018 The Authors. Published by Innovare Academic Sciences Pvt Ltd. This is an open access article under the CC BY license (http://creativecommons. org/licenses/by/4. 0/) DOI: http://dx.doi.org/10.22159/ajpcr.2018.v11i7.25780

\section{INTRODUCTION}

Periodontal diseases are very common among the general population. Gingivitis and periodontitis are the most commonly seen diseases. The body shows an inflammatory response due to the accumulation of the bacteria Gram-negative being the most predominant on the teeth surface [1].

Gingivitis is the inflammation of the gingiva. The inflammation of the gingiva can be due to various reasons such as plaque accumulation around the tooth surface, hormonal changes, druginduced, inflammatory, or idiopathic. There are four stages of gingival enlargement - the initial lesion, early lesion, established lesion, and advanced lesion. It is a reversible disease on proper maintenance of oral hygiene. Gingivitis is marked by red and swollen gums which bleed on probing and brushing of teeth. On proper maintenance of oral hygiene, brushing, flossing, and use of mouthwashes can reduce the condition. Gingivitis can be of two types which include plaque-induced gingival disease and non-plaque induced gingival disease. The plaque-induced gingival disease is mainly caused by the accumulation of plaque on the tooth surface and due to malnutrition or medications. The non-plaque induced gingival disease is caused because of any bacterial, fungal or viral infection, and foreign bodies in the oral cavity like dentures and can also be as a result of genetic factors. The accumulation of plaque around and on the tooth surface is the triggering factor for gingival inflammation due to the immune response and causing destruction of the tissues. When plaque is not removed regularly, it will calcify to become calculus and later can also form tartar on the tooth surface. There are also other reasons which will lead to the inflammation of the gingival tissues such as hormonal changes, drugs, smoking, diet leading to various deficiencies, and age. However, gingivitis, when left unattended, will lead to an increase destruction of the periodontal tissues causing an aggressive stage named periodontitis [1].

Periodontitis will lead to an excessive tissue destruction and bone loss which will eventually lead to mobility of teeth in the advanced stage. It damages the soft tissue and destroys the bone that supports the teeth. They have similar symptoms as gingivitis some aggravation. Red and swollen gingiva is seen which bleeds spontaneously on touch. Bad breath is also experienced in patients with periodontitis. The teeth will eventually become mobile and pain on biting will be experienced, and recession of the gingiva will be seen showing symptoms of sensitivity due to exposed roots. There are different types of periodontitis which include chronic periodontitis, aggressive periodontitis, and periodontitis as a manifestation of systemic disease. These diseases when confined to only a specific region of the oral cavity is called as localized, and when the disease is seen affecting the entire dentition, it is called as generalized. Chronic periodontitis is reported to have been seen most commonly in the older individuals in whom there is the excessive destruction of the tissues and bone. Aggressive periodontitis is the rapid destruction of the periodontium with the defects in the bone. It is most commonly said to be seen in individuals younger than 25 years of age but can be seen in adults also. The increase in the rate of progression of the disease will lead to early loss of teeth. This disease is mostly hereditary and can be seen in individuals having a family history of aggressive periodontitis. Early loss of teeth with early bone resorption is also seen in aggressive periodontitis and is a serious condition.

These diseases when left untreated or unattended will aggravate and eventually lead to loss of teeth and excessive bone resorption. In the aggravated stage the only treatment is the extraction of the teeth which we can mostly encounter because of the ignorance of the population to the periodontal problems. However, these diseases will become severe at the later stages and cause severe damage. Early detection of the disease will help in treating it and decreasing the severity of the disease. Therefore, planning on newer and safer drugs for the treatment of periodontal diseases will provide a better prognosis. Designing of drugs for the later stages will also be helpful in treating the disease. The new drugs being designed should be checked for its safety and its efficiency before using it of patients to avoid any adverse drug interaction or harm to the human 
body and its functions. These drugs are, hence, tested or experimented in animal models before using them in humans. The animals to be used must produce a similarity to the human anatomic structures and physiology. These similarities will help us to predict the clear safety of the drugs in humans as well. The periodontal diseases can be naturally occurring in these animals or have to be induced in them [2].

The bacterial biofilm will initiate the inflammatory responses causing these diseases. Various treatment modalities have to be found to reduce the harmful effects of the disease. The drugs and treatments to be planned have to be tested for its safety before being used in humans. New treatments are checked using animal models for their safety use and efficacy in humans. The treatment for the periodontal diseases should be emphasized on periodontal tissue regeneration using surgical and non-surgical methods, growth factors, bone substitutes, and mesenchymal stem cells which are the most recently proposed [2]. The most commonly used animals for inducing and treating periodontitis with newer ways are rats, pigs, hamsters, dogs, rabbits, and ferrets. These animals are first induced with the disease, and then the newer treatments are experimented on them to see its effect. However, these animal models must be used with utmost care for ethical reasons $[3,4]$. The animal models have given a lot of knowledge of new concerns in biological sciences [5-10].The use of animal models depends on the similarity of it to the human body. The animals chosen for periodontal research are checked for the close relationship to the human anatomy and physiology.

Periodontal research aims in finding the causes for periodontal diseases and inducing the diseases that are seen in the human oral cavity which includes creating bone defects and planning a proper treatment for it. The animals chosen are either having a periodontal disease, or the disease is induced in them, and various drugs are used for its treatment. The outcome of the treatment regarding the drugs and therapies is taken into consideration for periodontal diseases in humans.

\section{SELECTION OF ANIMAL MODELS}

The animals should have characteristics of the diseases similar to the ones seen in humans to study the evolution and origin of periodontal diseases. The experimental study should include the use of indices that are used in humans to assess the periodontal health such as the gingival index, oral hygiene index, and subgingival pocket depth. Experiments also require the use of radiographs, bacteria determination, histology analysis, and blood immunology assays.

The studies conducted using monkeys were of good importance since they had very similar anatomy to that of humans and also showed similar development of periodontal diseases. The research can be restricted in monkeys due to ethical reasons which require the care and use justifications. The transportation along with expenses should also be accounted for monkeys over long periods.

Dogs have a high occurrence of periodontal diseases with age and close relation with the etiopathogenesis of humans [11]. Dogs are used extensively in the periodontal research in spite of certain differences in the bacterial population and the inflammatory response compared to humans. The sub-connective tissue remains normal in dogs in spite of the calculus deposits leading to gingivitis which is contrary in humans. Gingivitis can be converted into periodontitis experimentally in dogs by ligature fixing around the tooth $[12,13]$.

The most ethically relevant animal models for periodontal research are the rodents and rats and have the dental structures similar to that of humans [14]. The periodontal diseases in rats are less compared to their occurrence in humans, so they are induced by bacterial inoculation and carbohydrate-rich diet or ligature around the teeth. However, the continuous growth and migration of teeth in rats do not make it possible to study the long period evolution of diseases histologically. However, these models are used for the immunological and microbiological studies [15].
Hamsters and rats share the similar etiopathogenesis of periodontal diseases. The hamsters are useful in microbiology and immunological researches [16].

Monkeys and dogs being large animals are widely used for treatments with different biomaterials and regeneration of tissues and pigs and rabbits are also for these researches to some extent. A literature research, in the past 10 years gave around 200 publications regarding the use of biomaterials and tissue engineering in experimental periodontitis.

The animal models were selected based on the ease in the surgically created defects and pathologies similar to humans. These defects can be created in the models in different ways which include the acute defect model, the chronic defect model, and the acute/chronic defect model.

The defects in acute defect models are surgically induced by removing the periodontal components surgically, and reproducible defects are created in the experiment and control sites. The chronic defects make use of the ligatures, orthodontic elastics, and silk sutures to reproduce the defects which are more commonly seen in the interproximal areas when compared to the buccal or lingual surfaces.

The chronic/acute defect is created surgically following by placement of ligatures to allow accumulation of calculus and to prevent the defect regeneration. The alveolar crest of the ramus is used to create osseous and periodontal defects. The sizes of the defects created are criticalsized and will heal over in time during the study.

The selection of animal models, however, gets compromise when dealing with large animals due to housing of these large animals and it also deals with the ethical and social issues. The role of bacteria, diet in the periodontal diseases in the histological level can be assessed by using small animals as models such as rats and hamsters.

\section{ANIMAL MODELS}

The animals which have a close resemblance to the human oral cavity are chosen for the periodontal research. These animal models are used to study the periodontal disease to design a better treatment and also to check the effectiveness of the treatment on that particular disease. Humans are said to have evolved from monkeys and hence showing maximum similarities to humans. However, dogs are also seen to naturally replicate the periodontal diseases seen in the humans. Rats have always been a part of the experimental world and are quite useful even in the periodontal field. The various animals commonly used to either replicate the periodontal diseases or naturally presenting the disease are rodents, pigs, dogs, rabbits, horses, ferrets, and hamsters.

\section{Non-human primates}

Monkeys are similar to humans and hence have a very close resemblance of the oral structures to humans and also the accumulation of plaque, calculus, and microbes. The species showing naturally occurring periodontal diseases are rhesus monkeys, baboons, and cynomolgus monkeys [17]. There are some species of non-human primates that show the periodontal diseases at the adult age [18]. The orthodontic elastics and ligatures were placed on the tooth surface to increase the plaque accumulation to induce periodontitis at a faster rate [3]. The ligatures are being changed every 1-2 weeks depending on the pocket formations [19-23].

\section{Dogs}

Dogs have plaque accumulation containing microbes similar to the human bacteria such as Porphyromonas gingivalis and Fusobacterium nucleatum [24,25]. The size and periodontal status of the dogs are similar to the human oral structures. The dogs that are most cooperative are employed in the research for the ease. The use of dogs however in a large scale is not possible due to ethical reasons. Although there are a lot of similarities between the human and dog dentition, there is a limitation to it when it comes to occlusion contacts, lateral movements, 
and open contacts. The gingivitis and periodontitis aggravation is similar to that seen in humans. Due to the accumulation of supragingival plaque and calculus because of the soft and minced diet will lead to aggravation of gingivitis [24-27].

The marginal part of the gingiva is inflamed in early gingivitis with neutrophils and monocytes. The later stages will lead to the extension of the infiltrate apically beyond the junctional epithelium leading to the pocket formation. The junctional epithelium and epithelial attachment will extend up to the coronal level on gingival margin, and hence the gingival sulcus is usually absent in healthy dogs.

There were two methods that were described which included treatment of surgical defects on $3^{\text {rd }}$ and $4^{\text {th }}$ mandibular premolars [28-30], or based after avulsion on $3^{\text {rd }}$ premolars [31-34]. The regeneration procedures which used bone morphogenetic protein, enamel matrix protein or grafting materials as bioactive glass, and guided tissue regeneration used were evaluated by these methods [35-38].

The residual osseous walls were counted at the surgical defect level and considered the important healing factor. For the evaluation of biomaterials, the defects having $4 \mathrm{~mm}$ of depth and width and osseous wall of 1 or 3 in number were reproduced in models for periodontal regeneration $[39,40]$. Dehiscence at the buccal roots level of the molars was induced in dogs.[41] The filling of biomaterials and regenerating techniques were done by creating fenestration of critical size at the maxillary canines on the buccal side [42-47].

\section{Miniature pigs}

In terms of disease development, anatomy and physiology the pigs are similar to humans [48]. The Minnesota miniature pig been used widely for the various biomedical researches [49]. The minipigs usually after the age of 6 months will develop gingivitis which will be indicated by inflammation of the gingiva, bleeding of the gingiva on probing and accumulation of plaque and calculus. The inoculation if bacteria and use of ligature wires will induce periodontitis in mini pigs in about 4-8 weeks [49].

\section{Rats}

The gingival area of the rats is very similar to the humans [14]. With all the similarities there exists some differences which include the crevicular epithelium keratinization and gingival and junctional epithelium relationship with contact of desmosomes between superficial cells of gingival epithelium and non-keratinized cells present in junctional epithelium [50]. The various changes occurring in the eruption of teeth in the rats will cause the movement of the molars in the three-dimensional space and lead to movement in an occlusal, distal, and buccal direction which is in comparison to the occluso mesial shift in human teeth. There is a shift if the cementoenamel junction occlusally faster when compared to the alveolar bone deposition. The age-related factors and changes will have an impact on the research regarding periodontal health and experiments. The rats appear normal in natural conditions, and hence the disease has to be induced in rats. The injections containing periodontal pathogens such as $P$. gingivalis, Streptococcus sobrinus, Aggregatibacter actinomycetemcomitans, Actinomyces viscosus, F. nucleatum, Capnocytophaga, and Eikenella corrodens are injected into the rats to induce the periodontal diseases [51].

The disease resistant strains in periodontics are obtained from silk ligatures tied around the molars such as Sprague-Dawley or white Lobund or can be done by inoculation of specific bacteria [52]. The inflammation is only localized to the junctional epithelium in the initial stage with high activity of phagocytes and neutrophils which forms a protective barrier. Acute interdental inflammation is seen as ulcerations in the junctional epithelium and neutrophils infiltrates in the supraalveolar connective tissue and increase in osteoclastic activity in 10\% of animals with 100 days of age [53,54].

A surgical model of rats has been proposed in the past 10 years [55]. This model had surgical periodontal defects on the second mandibular molars at the radicular surfaces in the form of fenestrations. The bone at the second molars following an extraoral incision was removed using a burr with saline irrigation. The depth of the defect was $1.5 \mathrm{~mm}$, and the width of $3 \mathrm{~mm}$ was standardized. This model of the rat was reprised by Huang [56].

The rats are small animals which have a relatively low housing and breeding cost and hence increasing the ease to carry out the researches in a successful and sufficient number for statistical analysis.

\section{Hamsters}

The histological structure of hamsters is similar to that of rats [57]. Diet with high concentration of carbohydrates was used to create periodontal disease in these animals [16]. The diet leads to a plaque accumulation consisting of formic acid bacteria with food debris seen in the palatal and lingual surfaces. Crater-like gingival pockets was formed after breakdown of plaque accumulation at the junctional epithelium and having the neutrophils as the primary inflammatory responses. However, in hamsters, the inflammatory response is limited when compared to rats and is different in observation to humans. The rats infected with Gram-positive bacteria showed similar periodontal lesions with diet in hamsters with the alveolar bone resorption mechanism.

\section{Ferrets}

The plaque was induced by ligatures in $4-8$ weeks [58,59]. The periodontal lesions observed in ferrets were similar to that of humans. The calculus quantity and quality increased with the progression of disease with inflammation following which there was a split in the junctional epithelium and hence the formation of gingival pockets similar to that seen in hamsters.

\section{Horses}

The most commonly seen diseases in horses are calculus accumulation, recession of gingiva, periodontal pocket, and buccal abrasion. Due to its large size and husbandry, the use of this animal is not much practiced for experimental research of periodontal diseases and to design newer therapies.

\section{Rabbits}

Various microorganisms were found in the rabbit oral cavity which included Arcanobacterium haemolyticum, F. nucleatum, Prevotella spp., Streptococcus milleri group, Peptostreptococcus micros, Actinomyces israelii, and Prevotella heparinolytica, which are similar to the flora of periodontal diseases seen in humans [60]. Surgically induced periodontal defects are created in the rabbits to study the periodontal regeneration, but the periodontal ligament regeneration was found to be less suitable $[61,11]$ periodontitis is caused by local factors such as plaque and calculus which leads to progressive inflammation causing bone loss $[62,63]$. Surgically induced defects may not mimic the natural form of disease.

\section{Minks}

Age- and plaque-related periodontitis is observed in minks. However, the severity of the disease is considered only in the older animals which show that the severity increases with aging in these animals. Aggressive periodontitis with severe periodontal lesions and bone loss is seen in younger minks.

The maxilla and mandible showed different extent of gingiva being affected with a deep vestibule in the upper jaw and large band of attached gingiva at the incisors and canines. The attached gingiva at the incisors and premolars in the lower jaw is narrower. The maxilla and mandible had the similar attached gingiva appearance at the molars. High hemorrhagic inflammatory response is seen in the marginal gingiva in minks affected by Chediac-Higashi syndrome. Bone crater formation is seen with variable bone resorption lesions at the furcation depending on the extent and location of the gingival inflammation. The inflammatory response, when seen histologically, appears different when compared to that of humans. Hence, these animals have an interesting role in the periodontal researches, but due to its housing, it is used in limitation. 


\section{CONCLUSION}

The different animals models used for periodontal research will have their own advantages and disadvantages. The use of the animal models depends on the accuracy and their similarity with that of the human oral cavity. The similarity of the animals to the human oral cavity will replicate the diseases as it is seen in humans and hence better treatment can be planned. The success of the treatment using various drugs can be assessed using these models. The naturally occurring periodontal diseases or the diseases have to be induced into the animal models to get an response. However, the use of some animals which show high similarity to the accumulation of plaque and deposits to that of human have been restricted their use due to its size and ethical reasons. The use of small animals is considered more comfortable and does not cause destruction in large scale. These small animals are induced with the periodontal disease and experiments of drugs are carried out.

These models are required for a better understanding of the origin and evolution of the diseases in humans. The animal models can help us to do a proper and effective periodontal research to make the use of new biomaterials and treatments successful in the clinical trials. The safety and efficacy of the new biomaterials and treatments depend on the similarity of the animal models anatomically, physiologically, and pathologically to humans.

The use of monkeys as animal's models is highly preferable due to its similarity in the anatomic and physiology of humans, but their use is limited due to the ethical reasons. Dogs are also widely used as animal models for periodontal research. The monkeys and dogs have anatomy and physiology similar to those of humans can be used for pre-clinical studies for new treatments. The use of rats requires the surgical creation of defects, but because of its small size, it is a most preferred model.

\section{AUTHOR'S CONTRIBUTION}

Both the authors contributed equally in preparing the manuscript, editing, and reviewing the article.

\section{CONFLICTS OF INTEREST}

Authors hereby declare that there are no conflicts of interest in this research.

\section{REFERENCES}

1. Shankari A. Awareness about periodontal disease and systemic disease among medical practitioners: A pilot study. J Contemp Dent 2016;6:104-7.

2. Tobita M, Uysal AC, Ogawa R, Hyakusoku H, Mizuno H. Periodontal tissue regeneration with adipose-derived stem cells. Tissue Eng Part A 2008; 14:945-53

3. Madden TE, Caton JG. Animal models for periodontal disease. Methods Enzymol 1994;235:106-19.

4. Selvig KA. Discussion: Animal models in reconstructive therapy. J Periodontol 1994:65:1169-72.

5. Li KL, Vogel R, Jeffcoat MK. The effect of ketoprofen creams on periodontal disease in rhesus monkeys. J Periodontal Res 1996;31:525-32.

6. Pavlica Z, Petelin M, Nemec A, Erzen D, Skaleric U. Measurement of total antioxidant capacity in gingival crevicular fluid and serum in dogs with periodontal disease. Am J Vet Res 2004;65:1584-8.

7. Holt SC, Ebersole J, Felton J, Brunsvold M, Kornman KS. Implantation of Bacteroides gingivalis in nonhuman primates initiates progression of periodontitis. Science 1988;239:55-7.

8. Klausen B. Microbiological and immunological aspects of experimental periodontal disease in rats: A review article. J Periodontol 1991;62:59-73.

9. Oz HS, Ebersole JL. A novel murine model for chronic inflammatory alveolar bone loss. J Periodontal Res 2010;45:94-9.

10. Cai X, Li C, Du G, Cao Z. Protective effects of baicalin on ligatureinduced periodontitis in rats. J Periodontal Res 2008;43:14-21.

11. Attström R, Graf-de Beer M, Schroeder HE. Clinical and histologic characteristics of normal gingiva in dogs. J Periodontal Res 1975;10:115-27.
12. Lindhe J, Ericsson I. Effect of ligature placement and dental plaque on periodontal tissue breakdown in the dog. J Periodontol 1978;49:343-50.

13. Soames JV, Davies RM. Lymphocyte-macrophage and lymphocytelymphocyte associations in early gingivitis in beagle dogs. J Periodontal Res 1980;15:341-4.

14. Yamasaki A, Nikai H, Niitani K, Ijuhin N. Ultrastructure of the junctional epithelium of germfree rat gingiva. J Periodontol 1979;50:641-8.

15. Peruzzo DC, Benatti BB, Antunes IB, Andersen ML, Sallum EA, Casati MZ, et al. Chronic stress may modulate periodontal disease: A study in rats. J Periodontol 2008;79:697-704.

16. Lallam-Laroye C, Escartin Q, Zlowodzki AS, Barritault D, Caruelle JP, Baroukh B, et al. Periodontitis destructions are restored by synthetic glycosaminoglycan mimetic. J Biomed Mater Res A 2006;79:675-83.

17. Schou S, Holmstrup P, Kornman KS. Non-human primates used in studies of periodontal disease pathogenesis: A review of the literature. J Periodontol 1993;64:497-508.

18. Priyanka M, Jaiganesh DR. Periodontally accelerated osteogenic orthodontics. Int J Pharm PharmSci 2013;5:49-51.

19. Holt SC, Brunsvold M, Jones A, Wood R, Ebersole JL. Cell envelope and cell wall immunization of Macaca fascicularis: Effect on the progression of ligature-induced periodontitis. Oral Microbiol Immunol 1995; 10:321-33.

20. Ebersole JL, Brunsvold M, Steffensen B, Wood R, Holt SC. Effects of immunization with Porphyromonas gingivalis and Prevotella intermedia on progression of ligature-induced periodontitis in the nonhuman primate Macaca fascicularis. Infect Immunity 1991;59:3351-9.

21. Kornman KS, Holt SC, Robertson PB. The microbiology of ligatureinduced periodontitis in the cynomolgus monkey. J Periodontal Res 1981;16:363-71.

22. Weinreb M, Quartuccio H, Seedor JG, Aufdemorte TB, Brunsvold M, Chaves E, et al. Histomorphometrical analysis of the effects of the bisphosphonate alendronate on bone loss caused by experimental periodontitis in monkeys. J Periodontal Res 1994;29:35-40.

23. Persson GR, Engel LD, Moncla BJ, Page RC. Macaca nemestrina: A non-human primate model for studies of periodontal disease. J Periodontal Res 1993;28:294-300.

24. Egelberg J. local effect of diet on plaque formation and development of gingivitis in dogs. I. Effect of hard and soft diets. Odontol Revy 1965;16:31-41.

25. Hamp SE, Lindhe J, Löe H. Experimental periodontitis in the beagle dog. J Periodont Res 1972;10:13-4.

26. Egelberg J. local effect of diet on plaque formation and development of gingivitis in dogs 3 . Effect of frequency of meals and tube feeding. Odontol Revy 1965;16:50-60.

27. Lindhe J, Hamp S, Loe H. Experimental periodontitis in the beagle dog. J Periodontal Res 1973;8:1-10.

28. Wikesjö UM, Lim WH, Razi SS, Sigurdsson TJ, Lee MB, Tatakis DN, et al. Periodontal repair in dogs: A bioabsorbable calcium carbonate coral implant enhances space provision for alveolar bone regeneration in conjunction with guided tissue regeneration. J Periodontol 2003;74:957-64

29. Wikesjö UM, Qahash M, Thomson RC, Cook AD, Rohrer MD, Wozney JM, et al. Space-providing expanded polytetrafluoroethylene devices define alveolar augmentation at dental implants induced by recombinant human bone morphogenetic protein 2 in an absorbable collagen sponge carrier. Clin Implant Dent Relat Res 2003;5:112-23.

30. Wikesjö UM, Xiropaidis AV, Thomson RC, Cook AD, Selvig KA, Hardwick WR, et al. Periodontal repair in dogs: RhBMP-2 significantly enhances bone formation under provisions for guided tissue regeneration. J Clin Periodontol 2003;30:705-14.

31. Araújo MG, Berglundh T, Lindhe J. GTR treatment of degree III furcation defects with 2 different resorbable barriers. An experimental study in dogs. J Clin Periodontol 1998;25:253-9.

32. Araújo MG, Lindhe J. GTR treatment of degree III furcation defects following application of enamel matrix proteins. An experimental study in dogs. J Clin Periodontol 1998;25:524-30.

33. Araújo MG, Berglundh T, Albrekstsson T, Lindhe J. Bone formation in furcation defects. An experimental study in the dog. J Clin Periodontol 1999;26:643-52.

34. Roriz VM, Souza SL, Taba M Jr., Palioto DB, Grisi MF. Treatment of class III furcation defects with expanded polytetrafluoroethylene membrane associated or not with anorganic bone matrix/synthetic cellbinding peptide: A histologic and histomorphometric study in dogs. J Periodontol 2006;77:490-7.

35. Fernandes JM, Rego RO, Spolidorio LC, Marcantonio RA, Marcantonio Júnior E, Cirelli JA, et al. Enamel matrix proteins associated with GTR and bioactive glass in the treatment of class III furcation in dogs. Braz 
Oral Res 2005; 19:169-75.

36. Onodera H, Shibukawa Y, Sugito H, Ota M, Yamada S. Periodontal regeneration in intrabony defects after application of enamel matrix proteins with guided tissue regeneration: An experimental study in dogs. Biomed Res 2005;26:69-77.

37. Pimentel SP, Sallum AW, Saldanha JB, Casati MZ, Nociti FH Jr., Sallum EA, et al. Enamel matrix derivative versus guided tissue regeneration in the presence of nicotine: A histomorphometric study in dogs. J Clin Periodontol 2006;33:900-7.

38. Sallum EA, Pimentel SP, Saldanha JB, Nogueira-Filho GR, Casati MZ, Nociti FH, et al. Enamel matrix derivative and guided tissue regeneration in the treatment of dehiscence-type defects: A histomorphometric study in dogs. J Periodontol 2004; 75:1357-63.

39. Sakata J, Abe H, Ohazama A, Okubo K, Nagashima C, Suzuki M, et al. Effects of combined treatment with porous bovine inorganic bone grafts and bilayer porcine collagen membrane on refractory one-wall intrabony defects. Int J Periodontics Restorative Dent 2006;26:161-9.

40. Kim CS, Choi SH, Chai JK, Cho KS, Moon IS, Wikesjö UM, et al. Periodontal repair in surgically created intrabony defects in dogs: Influence of the number of bone walls on healing response. J Periodontol 2004;75:229-35

41. da Silva Pereira SL, Sallum AW, Casati MZ, Caffesse RG, Weng D, Nociti FH Jr., et al. Comparison of bioabsorbable and nonresorbable membranes in the treatment of dehiscence-type defects. A histomorphometric study in dogs. J Periodontol 2000;71:1306-14.

42. Tal H, Pitaru S, Moses O, Kozlovsky A. Collagen gel and membrane in guided tissue regeneration in periodontal fenestration defects in dogs. J Clin Periodontol 1996;23:1-6.

43. Tal H, Artzi Z, Moses O, Nemcovsky C, Kozlovsky A. Guided periodontal regeneration using bilayered collagen membranes and bovine bone mineral in fenestration defects in the canine. Int $\mathrm{J}$ Periodontics Restorative Dent 2005;25:509-18.

44. Caplanis N, Lee MB, Zimmerman GJ, Selvig KA, Wikesjö UM. Effect of allogenic freeze-dried demineralized bone matrix on guided tissue regeneration in dogs. J Periodontol 1998;69:851-6.

45. Doğan A, Ozdemir A, Kubar A, Oygür T. Healing of artificial fenestration defects by seeding of fibroblast-like cells derived from regenerated periodontal ligament in a dog: A preliminary study. Tissue Eng 2003;9:1189-96.

46. Klepp M, Hinrichs JE, Eastlund T, Schaffer EM. Histologic evaluation of demineralized freeze-dried bone allografts in barrier membrane covered periodontal fenestration wounds and ectopic sites in dogs. J Clin Periodontol 2004;31:534-44.

47. Vastardis S, Yukna RA, Mayer ET, Atkinson BL. Periodontal regeneration with peptide-enhanced anorganic bone matrix in particulate and putty form in dogs. J Periodontol 2005;76:1690-6.

48. Wang S, Liu Y, Fang D, Shi S. The miniature pig: A useful large animal model for dental and orofacial research. Oral Dis 2007;13:530-7.

49. Polejaeva IA, Chen SH, Vaught TD, Page RL, Mullins J, Ball S, et al. Cloned pigs produced by nuclear transfer from adult somatic cells. Nature 2000;407:86-90.

50. Listgarten MA. Similarity of epithelial relationships in the gingiva of rat and man. J Periodontol 1975;46:677-80.

51. Klausen B. Microbiological and immunological aspects of experimental periodontal disease in rats: A review article. J Periodontol 1991;62:59-73.

52. Guessous F, Huynh C, N'Guyen H, Godeau G, Giroud JP, Meyer J, et al. An animal model for the assessment of gingival lesions. J Pharmacol Toxicol Methods 1994;32:161-7.

53. Garant PR, Cho MI. Histopathogenesis of spontaneous periodontal disease in conventional rats. II. Ultrastructural features of the inflamed subepithelial connective tissue. J Periodontal Res 1979;14:310-22.

54. Garant PR, Cho MI. Histopathogenesis of spontaneous periodontal disease in conventional rats. Histometric and histologic study. J Periodontal Res 1979;14:297-309.

55. King GN, King N, Cruchley AT, Wozney JM, Hughes FJ. Recombinant human bone morphogenetic protein-2 promotes wound healing in rat periodontal fenestration defects. J Dent Res 1997;76:1460-70.

56. Huang KK, Shen C, Chiang CY, Hsieh YD, Fu E. Effects of bone morphogenetic protein- 6 on periodontal wound healing in a fenestration defect of rats. J Periodontal Res 2005;40:1-0.

57. Eggert FM, Germain JP, Cohen B. The gingival epithelium of rodent molars with limited eruption. Acta Anat (Basel) 1980;107:297-306.

58. Harper DS, Mann PH, Regnier S. Measurement of dietary and dentifrice effects upon calculus accumulation rates in the domestic ferret. J Dent Res 1990;69:447-50.

59. Mann PH, Harper DS, Regnier S. Reduction of calculus accumulation in domestic ferrets with two dentifrices containing pyrophosphate. J Dent Res 1990;69:451-3.

60. Tyrrell KL, Citron DM, Jenkins JR, Goldstein EJ. Periodontal bacteria in rabbit mandibular and maxillary abscesses. J Clin Microbiol 2002;40:1044-7.

61. Oortgiesen DA, Meijer GJ, Bronckers AL, Walboomers XF, Jansen JA. Fenestration defects in the rabbit jaw: An inadequate model for studying periodontal regeneration. Tissue Eng Part C Methods 2010;16:133-40.

62. Priyanka M, Ramamurthy J. Tissue engineering in periodontal regeneration. Res J Pharm Bio Chem Sci 2015;69:78-82.

63. Ranganatha N, Kuppast IJ. A review on alternatives to animal testing methods in drug development. Int J Pharm Pharm Bio Sci 2012;4:28-32. 